\title{
Physico-Chemical Stability of Busulfan in Injectable Solutions in Various Administration Packages
}

\author{
Mélanie Houot • Vianney Poinsignon • \\ Lionel Mercier $\cdot$ Cyril Valade $\cdot$ Romain Desmaris • \\ François Lemare $\cdot$ Angelo Paci
}

Published online: 3 April 2013

(c) The Author(s) 2013. This article is published with open access at Springerlink.com

\begin{abstract}
Background and Objectives Busulfan is used as part of a conditioning regimen prior to hematopoietic stem cell transplantation for the treatment of certain cancers and immune deficiency syndromes. Due to its instability in aqueous preparations, busulfan for infusion is prepared from a concentrate and has a relatively short shelf life once prepared. The purpose of this study was to identify the most suitable storage container and temperature to maximize the shelf life of busulfan therapeutic infusions prepared from Busilvex ${ }^{\circledR}$.

Methods Busilvex ${ }^{\circledR} 6 \mathrm{mg} / \mathrm{mL}$ was diluted to $0.55 \mathrm{mg} / \mathrm{mL}$ with $0.9 \% \mathrm{NaCl}$ and aliquots dispensed into polypropylene syringes, polyvinyl chloride bags, and glass bottles. Three storage temperatures were evaluated: $2-8{ }^{\circ} \mathrm{C}$, $13-15^{\circ} \mathrm{C}$ (thermostatically controlled chamber), and room temperature $\left(20 \pm 5^{\circ} \mathrm{C}\right)$. At set time points, samples were analysed for busulfan content, using a high-performance liquid chromatography (HPLC) system with ultraviolet detection. The change in $\mathrm{pH}$ and osmolarity on storage was also determined, and solutions were inspected visually for formation of a precipitate or colour change. To determine the contribution of precipitation to loss of busulfan content on storage, samples from one time series were treated with
\end{abstract}

\footnotetext{
M. Houot · V. Poinsignon · L. Mercier · A. Paci ( $\varangle)$ Pharmacology and Drug Analysis Department, Institut de Cancérologie Gustave Roussy, 114, rue Edouard Vaillant, 94805 Villejuif Cedex, France e-mail: angelo.paci@igr.fr

M. Houot - V. Poinsignon - L. Mercier · C. Valade .

R. Desmaris · F. Lemare · A. Paci

Clinical Pharmacy Department, Institut de Cancérologie Gustave

Roussy, 114, rue Edouard Vaillant, 94805 Villejuif Cedex, France
}

the solvent dimethylacetamide prior to HPLC separation and quantitation of busulfan.

Results The results of the active substance content monitoring study over a 48 -h period demonstrate that busulfan solution is stable at a $5 \%$ threshold, at $2-8{ }^{\circ} \mathrm{C}$ for $16 \mathrm{~h}$ in syringes, $14 \mathrm{~h}$ in glass bottles, and $6 \mathrm{~h}$ in bags. In addition, the period of stability decreases as the temperature increases $\left(4 \mathrm{~h}\right.$ at $20 \pm 5^{\circ} \mathrm{C}$ ). The solution is considered to be stable, subject to precipitation liable to be observed regardless of the temperature.

Conclusion The best stability was observed for busulfan solutions placed at $2-8{ }^{\circ} \mathrm{C}$ in syringes. This study demonstrated that precipitation, in addition to hydrolysis, has a significant influence on the busulfan content.

\section{Introduction}

Busulfan (1,4-butanediol dimethanesulphonate) is an alkylating agent used extensively for its anti-tumor properties, characterized in the early 1950s by Galton et al. for the treatment of chronic myeloid leukemia (CML) [1]. Intravenous busulfan was developed to overcome the dosing issues associated with the oral form of the drug (reviewed by Scott et al., 2012 [2]).

Currently, busulfan is indicated for use in conjunction with other agents for conditioning prior to hematopoietic stem cell (HSC) transplantation [2,3]. For adults, it is used in conjunction with cyclophosphamide (BuCy2 regimen), whereas for pediatric patients (aged 0-17 years), it can be used in conjunction with either melphalan (BuMel) or cyclophosphamide (BuCy4) [2]. These conditioning regimens prior to allogenic or autologous HSC transplantation are used to treat a large number of malignant diseases such as leukemia and some solid tumors, as well as genetic 
diseases such as immune deficiency syndromes [4-7]. Other combinations associate busulfan with thiotepa. More recently, less myoloablative combinations with fludarabine (BuFlu) have shown efficacy while offering lower extrahematological toxicity $[8,9]$.

According to the Summary of Product Characteristics (SPC), Busulfan (Busilvex ${ }^{\circledR}$ ) is administered intravenously (IV) at a recommended dose of $0.8 \mathrm{mg} / \mathrm{kg}$ in adults and $0.8-1.2 \mathrm{mg} / \mathrm{kg}$ (depending on bodyweight) in pediatric patients [3]. It is administered by means of a 2 -h infusion every $6 \mathrm{~h}$ for 4 consecutive days (giving a total of 16 doses). Because of its highly predictable linear pharmacokinetics, once-daily administrations are under evaluation in adults [10]. Busulfan is provided as a $6 \mathrm{mg} / \mathrm{mL}$ concentrate and once it has been reconstituted in the form of a $0.55 \mathrm{mg} / \mathrm{mL}$ solution, the stability data provided by Pierre Fabre Laboratories are $8 \mathrm{~h}$ at $20 \pm 5^{\circ} \mathrm{C}$ (room temperature [RT]) or $12 \mathrm{~h}$ at $2-8{ }^{\circ} \mathrm{C}$ followed by $3 \mathrm{~h}$ at RT. More recently, a German study reported a period of stability of $36 \mathrm{~h}$ at a temperature between 13 and $15{ }^{\circ} \mathrm{C}$ for the same solutions diluted to a $0.5 \mathrm{mg} / \mathrm{mL}$ dose and prepared in polypropylene (PP) bags or glass bottles [11, 12]. Busulfan undergoes a hydrolysis phenomenon in aqueous media, giving rise to methanesulphonic acid and tetrahydrofuran (THF) [13]. A precipitation phenomenon was also identified during these studies [11].

The short shelf life specified in the SPC combined with the administration regimen of every $6 \mathrm{~h}$ for 4 consecutive days poses organizational problems for chemotherapy preparation, particularly at the end of the week.

The purpose of our study was to investigate the stability of busulfan injection solution (Busilvex ${ }^{\circledR}$ ) diluted in $0.9 \%$ sodium chloride $(\mathrm{NaCl})$ to a concentration of $0.55 \mathrm{mg} / \mathrm{mL}$ (the recommended concentration for administration) in three different containers: PP syringes, polyvinyl chloride (PVC) bags, and glass bottles, when stored at three different temperatures $\left(2-8,13-15\right.$, and $\left.20 \pm 5{ }^{\circ} \mathrm{C}\right)$. We monitored changes in the busulfan content of this solution, its $\mathrm{pH}$, and its osmolality over time, and sought to understand the phenomena causing the busulfan content to decrease.

\section{Materials and Methods}

\subsection{Materials and Reagents}

Busulfan (Fig. 1) (Fluka, Steinheim, Germany; purity $\geq 99 \%$ ) was used to produce the series of standard solutions for calibration and the quality controls. Diethyldithiocarbamate (Fig. 1) (Sigma-Aldrich, St Louis, MO, USA) was used to prepare the derivatization solution each day. The Busilvex ${ }^{\circledR}$ used for the preparations was supplied by Pierre Fabre Oncologie, Boulogne, France. The internal standard (IS) solutions were prepared with dibromopentane (Fig. 1) (Aldrich, Steinheim, Germany), diluted in ethanol (VWR, Fontenay-sous-Bois, France).

The high-performance liquid chromatography (HPLC) system consisted of a quaternary pump (Merck Hitachi ${ }^{\circledR}$ L7100), an automatic injector (Merck Hitachi ${ }^{\circledR}$ L2200), an ultraviolet (UV) visible detector (Waters ${ }^{\circledR}$ 2487), and Multi HSM Manager software (Merck Hitachi ${ }^{\circledR}$ ).

The analysis was run using an Agilent Zorbax ${ }^{\circledR}$ SB C18 column $(5 \mu \mathrm{m}, 150 \times 4.6 \mathrm{~mm})$ (Agilent Technologies). The column was thermostatically controlled at $40{ }^{\circ} \mathrm{C}$ during use and then rinsed with a water $\left(\mathrm{H}_{2} \mathrm{O}\right) /$ methanol (50/ $50, \mathrm{v} / \mathrm{v})$ mixture.

Busulfan was detected by absorbance at $281 \mathrm{~nm}$. In isocratic mode, a mobile phase consisting of acetonitrile (ACN), $\mathrm{H}_{2} \mathrm{O}$, and trifluoroacetic acid (TFA) (proportions: $650 / 350 / 1, \mathrm{v} / \mathrm{v} / \mathrm{v}$ ) was run through the system at a flow rate of $2 \mathrm{~mL} / \mathrm{min}$.

\subsection{Sample Preparation, Storage, and Processing}

Busulfan preparations were produced by diluting the product Busilvex ${ }^{\circledR}$ in $0.9 \% \mathrm{NaCl}$ to obtain a final concentration of $0.55 \mathrm{mg} / \mathrm{mL}$ (therapeutic concentration). The containers used for the preparations were PP syringes (Becton Dickinson, Franklin Lakes, NJ, USA; $50 \mathrm{~mL}$, ref: 300865), EasyFlex ${ }^{\circledR}$ PVC bags (MacoPharma, Tourcoing, France) and 250-mL glass bottles containing $0.9 \% \mathrm{NaCl}$ (CDM Lavoisier, Paris, France). Busulfan solutions were<smiles>CS(=O)(=O)OCCCCOS(C)(=O)=O</smiles>

B

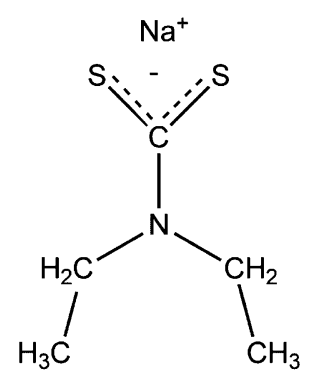

C

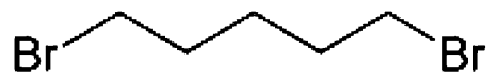

Fig. 1 Chemical structures of a busulfan (1,4-butanediol dimethanesulphonate), b diethyldithiocarbamate, and c dibromopentane 
then aliquoted into smaller containers so that the solutions remained under the defined storage conditions throughout the evaluation period. These containers were $3-\mathrm{mL}$ PP syringes (Becton Dickinson; ref: 300910), 50-mL EasyFlex ${ }^{\circledR}$ PVC bags (MacoPharma) and 2-mL glass bottles (Schott, St Gallen, Switzerland; ref: VCDIN2R) of borosilicate pharmaceutical type I glass adapted for injections, fitted with chlorobutyl stoppers.

The storage conditions for each of the containers were $2-8{ }^{\circ} \mathrm{C}, 13-15{ }^{\circ} \mathrm{C}$ (thermostatically controlled chamber), and, finally, RT $\left(20 \pm 5^{\circ} \mathrm{C}\right)$. For each of the conditions (container and storage temperature), a sample was processed and analysed by HPLC-UV either every $6 \mathrm{~h}$ or every $3 \mathrm{~h}$.

Samples were processed in glass tubes because of the use of dimethylacetamide (DMA). To $0.5 \mathrm{~mL}$ of aliquot, we added $0.5 \mathrm{~mL}$ of DMA, followed by $0.1 \mathrm{~mL}$ of IS. After stirring, $1.0 \mathrm{~mL}$ of DMA and $0.5 \mathrm{~mL}$ of derivatization agent were added for a final volume of $2.6 \mathrm{~mL}$. The solution was stirred a second time before being left to stand for $1 \mathrm{~h}$ at $\mathrm{RT}$, the time required for derivatization prior to injection. A $30-\mu \mathrm{L}$ test sample was then injected into the chromatographic system.

\subsection{Transfer and Validation of Method}

We adapted the analytical method registered by Pierre Fabre Laboratories in the marketing authorization application. The validation of this method was conducted at our laboratory according to International Conference on Harmonisation (ICH) topic Q2R guidelines [14]. We thus assessed the linearity, precision (i.e. repeatability and intermediate precision), and accuracy of our method. The method was shown to be linear over a concentration range from 0.05 to $0.5 \mathrm{mg} / \mathrm{mL}$.

Under these chromatographic conditions, busulfan and dibromopentane separated correctly with respective retention times of 9.6 and $13.3 \mathrm{~min}$ (Fig. 2). The chromatographic peak observed at $3.3 \mathrm{~min}$ consisted of the unreacted compound diethyl dithiocarbamate.

\subsection{Study Procedure}

The stability of busulfan at the therapeutic concentration of $0.55 \mathrm{mg} / \mathrm{mL}$ was assessed in the three containers and at the three temperatures defined above. The assessments were conducted in two stages: for the first stage, four analyses were conducted for each series $(n=9)$ and for time points of the 48-h period of study $(n=9)$. For the second one, six analyses were conducted for each series $(n=9)$ and for each time point of the 15 -h period of study $(n=6)$.

\subsection{Busulfan Content Monitoring}

The first section of the study covered $48 \mathrm{~h}$ with one analysis every $6 \mathrm{~h}$. In order to conduct all of the analyses during laboratory opening hours, the preparations were produced in two series with a 6-h interval. For each series, two preparations were generated for the content analyses and a further three preparations per container were generated to assess the loss of mass.

The second section was conducted over a 15 -h period. It consisted of first performing an analysis of the samples over a shorter period with samples taken every $3 \mathrm{~h}$ in order to determine a more precise period of stability. In addition, it consisted of investigating the decrease in busulfan content on storage, so as to understand whether this decrease was due mainly to busulfan degradation or precipitation. To do this, we performed a second assay on the same samples, but after adding DMA to the solution directly in the container (1:4 dilution of initial sample). After homogenization, a 2-mL test sample was analysed after adding $0.1 \mathrm{~mL}$ of IS and $0.5 \mathrm{~mL}$ of derivatization agent. DMA is the solvent of choice for busulfan and should enable the solubilization of any precipitate.

We considered that at time zero $\left(T_{0}\right)$, the initial concentration $\left(C_{0}\right)$ of the active substance was $100 \%$. The contents for each analysis time were thus determined on the basis of $C_{0}$. According to these conditions, the solutions were considered to be stable if their content was greater than $90 \%$, the threshold used by hospital pharmacists and in the Karstens' study, or $95 \%$, the threshold used by the pharmaceutical industry, such as Pierre Fabre, of $C_{0}$.

\subsection{Organoleptic Characteristics and Visual Inspection}

The stability of the preparations under the various conditions was studied macroscopically by observing whether a precipitate or crystallization, or a change of colour, appeared.

\subsection{Study of $\mathrm{pH}$ and Osmolarity}

The $\mathrm{pH}$ of each aliquot was measured using a Metrohm 713 pH meter equipped with a Pt 1000 electrode (Metrohm, Villebon Courtaboeuf, France) after calibration and analysis of a control solution set at $\mathrm{pH} 7$ prior to each series of measurements.

For each sample, an osmolarity measurement was made with a Roebling automatic osmometer (Roebling, Berlin, Germany) with a prior analysis of a calibration solution set at $300 \mathrm{mOsm} / \mathrm{L}$. 
Fig. 2 Chromatogram of busulfan diluted in $0.9 \%$ sodium chloride at $0.55 \mathrm{mg} / \mathrm{mL}$. The peak at $9.6 \mathrm{~min}$ is busulfan, and the peak at $13.3 \mathrm{~min}$ is dibromopentane

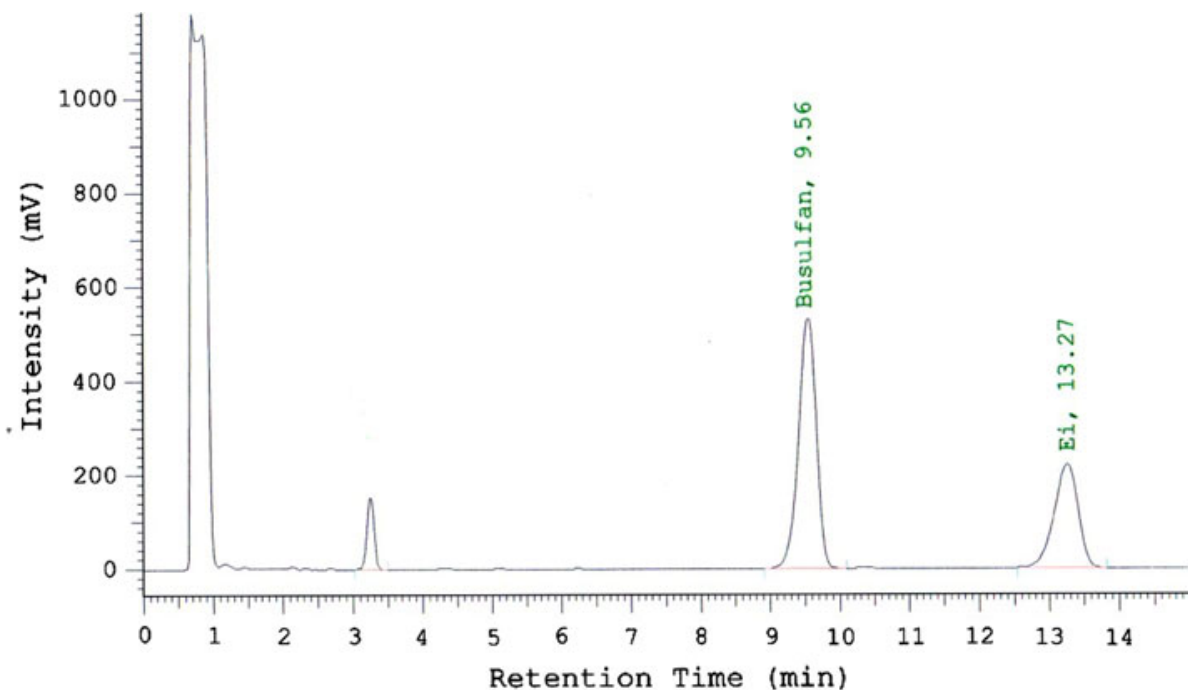

\section{Results}

The busulfan concentration was assessed at the $5 \%$ threshold, as applied in the Pierre Fabre Laboratories study, to account for the overall stability of the pharmaceutical product and at a $10 \%$ threshold to compare our results with those obtained in a previous study by Karstens and Krämer [11].

Results of the $48 \mathrm{~h}$ series are shown in Fig. 3. When stored at $2-8{ }^{\circ} \mathrm{C}$, dilute busulfan solutions were stable for longer in PP syringes (i.e. $16 \mathrm{~h}$ at a $5 \%$ threshold and $24 \mathrm{~h}$ at a $10 \%$ threshold) than in PVC bags (6 h at a $5 \%$ threshold and $8 \mathrm{~h}$ at a $10 \%$ threshold) or glass bottles (14 h at a $5 \%$ threshold and $18 \mathrm{~h}$ at a $10 \%$ threshold). Busulfan was more stable when stored at $2-8{ }^{\circ} \mathrm{C}$, regardless of the container, than at higher temperatures $(16 \mathrm{~h}$ vs. $8 \mathrm{~h}$ at $13-15{ }^{\circ} \mathrm{C}$ or $4 \mathrm{~h}$ at RT based on a $5 \%$ threshold in syringes, for example).

Results of the $15 \mathrm{~h}$ series, with sampling every $3 \mathrm{~h}$, are shown in Table 1; they confirmed that PP syringes offered the best stability, regardless of storage temperature.

Macroscopic analysis of the solutions revealed the random appearance of a visible precipitate regardless of the container and the storage temperature.

Regarding the $\mathrm{pH}$ of solutions, during the first $12 \mathrm{~h}$ of storage, a reduction of $0.8-1.2 \mathrm{pH}$ units was observed in solutions prepared in PP syringes compared with 0.9-1.2 units for those prepared in glass and 1.6-1.8 units for those prepared in PVC bags. The results are presented in Table 2. This decrease could be explained by the release of methanesulphonic acid that occurs during busulfan degradation. However, it should be noted that the $\mathrm{pH}$ values measured throughout the study remain compatible with intravenous administration.

Osmolarity changes (between 0 and $48 \mathrm{~h}$ ) appear to be consistent with the stability described above: at $2-8{ }^{\circ} \mathrm{C}$, there is no significant difference in osmolarity, regardless of the container used; at $13-15{ }^{\circ} \mathrm{C}$, osmolarity is significantly different in PVC bags $(p<0.05, p=0.002)$ and in glass bottles $(p<0.05, p=0.003)$. At RT, osmolarity is significantly different $(p<0.05$; PVC, $p=0.004$; PP, $p=0.04$; glass, $p=0.03$ ) regardless of the container used.

In the second part to the study, an analysis was run on the same samples under the same conditions but after first adding DMA to solubilize any precipitated busulfan. At each analysis time and condition, a difference in busulfan content between the two assays was observed such that the busulfan content after adding DMA was greater than 90 or $95 \%$ of the initial concentration. At $12 \mathrm{~h}$, in PVC bags stored at $2-8{ }^{\circ} \mathrm{C}$, the busulfan content was $40.9 \%$, whereas after adding DMA the content increased to $85.9 \%$. In the same conditions, in PP syringes the content did not differ after adding DMA$100.3 \%$ before vs. $104.5 \%$ after. This suggested that the main factor causing the decrease in the busulfan content with time was indeed the precipitation phenomenon.

\section{Discussion}

Our study data differ somewhat from other reports on the stability of busulfan solutions. The divergences observed between the different studies can be partly explained by non-identical study conditions and parameters. Indeed, whereas Pierre Fabre Laboratories who market Busilvex ${ }^{\circledR}$ recommend a shelf-life in PP syringes or in PVC bags of $12 \mathrm{~h}$ at $2-8{ }^{\circ} \mathrm{C}$ followed by $3 \mathrm{~h}$ at RT [3], the study by Karstens and Krämer [11] found a greater period of stability $(19 \mathrm{~h})$ at the same temperature in syringes. Indeed, the study conducted by the manufacturer made its conclusions on the basis of a $5 \%$ threshold, whereas the German study, conducted in a hospital environment, used a $10 \%$ specification threshold for refrigerated storage only. 
Fig. 3 Stability of busulfan $(0.55 \mathrm{mg} / \mathrm{mL})$ diluted in $0.9 \%$ sodium chloride and stored at a $2-8{ }^{\circ} \mathrm{C}$, b $13-15^{\circ} \mathrm{C}$, or c room temperature $\left(20 \pm 5^{\circ} \mathrm{C}\right)$. Busulfan content was monitored over $48 \mathrm{~h}$ (one analysis every $6 \mathrm{~h}$ ). Data are presented as mean \pm standard deviation ( $n=8$ for $T_{0}, n=4$ for other analysis times). $P P$ polypropylene, $P V C$ polyvinyl chloride
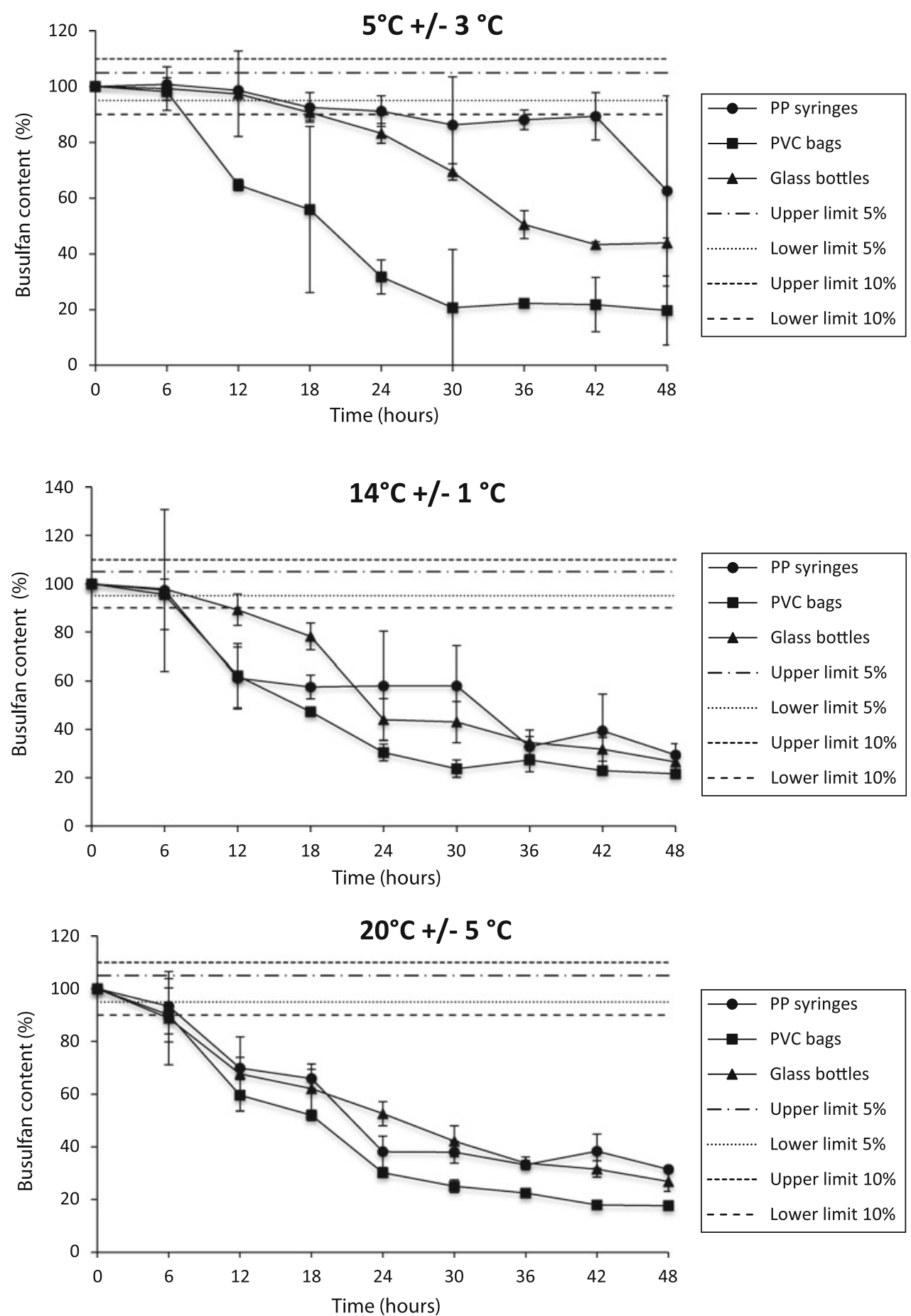

Comparing the three containers evaluated in this study, our results demonstrate that the PP syringe offers the best storage regardless of temperature. This is in contrast to the results of the German study, which demonstrated that glass is more suitable, giving 48 or $36 \mathrm{~h}$ of stability depending on the storage temperature. Senoo and co-workers [15] also demonstrated that colourless PP syringes offered good stability for busulfan, with their data indicating that under refrigeration, busulfan solution was physically and chemically stable for up to $96 \mathrm{~h}$.

Other storage containers are available, including polyolefin/polyamide laminate packs. A recent study evaluated the stability of busulfan solutions when stored in such packs. Busulfan solutions were prepared in physiological saline at $0.24 \mathrm{mg} / \mathrm{mL}$ and at $0.12 \mathrm{mg} / \mathrm{mL}$ and stored under refrigeration or at RT [16]. Regardless of the drug 
Table 1 Stability of busulfan $(0.55 \mathrm{mg} / \mathrm{mL})$ under different storage conditions. Busulfan content was monitored over $15 \mathrm{~h}$ (one analysis every $3 \mathrm{~h}$ )

\begin{tabular}{|c|c|c|c|c|c|c|c|}
\hline \multirow[t]{2}{*}{ Container } & \multirow{2}{*}{$\begin{array}{l}\text { Temperature } \\
\left({ }^{\circ} \mathrm{C}\right)\end{array}$} & \multirow{2}{*}{$\begin{array}{l}\text { Initial concentration }^{\mathrm{a}} \\
(\mathrm{mg} / \mathrm{mL})\end{array}$} & \multicolumn{5}{|c|}{ Percentage of initial concentration remaining ${ }^{a}$} \\
\hline & & & $3 \mathrm{~h}$ & $6 \mathrm{~h}$ & $9 \mathrm{~h}$ & $12 \mathrm{~h}$ & $15 \mathrm{~h}$ \\
\hline \multirow[t]{3}{*}{ PP syringes } & 4 & $0.240 \pm 0.2$ & $101.5 \pm 1.3$ & $100.7 \pm 1.3$ & $100.9 \pm 1.2$ & $100.3 \pm 1.1$ & $100.4 \pm 1.0$ \\
\hline & 13 & $0.238 \pm 0.7$ & $100.5 \pm 3.2$ & $99.1 \pm 2.8$ & $97.4 \pm 4.1$ & $94.3 \pm 3.4$ & $92.5 \pm 4.2$ \\
\hline & 20 & $0.236 \pm 0.9$ & $100.2 \pm 3.7$ & $97.1 \pm 1.6$ & $95.8 \pm 1.5$ & $93.8 \pm 1.9$ & $91.7 \pm 1.7$ \\
\hline \multirow[t]{3}{*}{ PVC bags } & 4 & $0.279 \pm 0.5$ & $97.9 \pm 2.9$ & $90.9 \pm 6.2$ & $49.7 \pm 8.5$ & $40.9 \pm 4.5$ & $14.9 \pm 2.5$ \\
\hline & 13 & $0.230 \pm 0.4$ & $97.1 \pm 2.1$ & $97.3 \pm 2.6$ & $80.8 \pm 4.7$ & $65.0 \pm 5.8$ & $39.1 \pm 5.9$ \\
\hline & 20 & $0.283 \pm 1.4$ & $94.6 \pm 5.1$ & $97.0 \pm 4.1$ & $91.9 \pm 4.3$ & $88.5 \pm 6.6$ & $82.4 \pm 12.1$ \\
\hline \multirow[t]{3}{*}{ Glass bottles } & 4 & $0.290 \pm 2.7$ & $79.9 \pm 6.7$ & $57.3 \pm 18.3$ & $45.5 \pm 12.3$ & $35.4 \pm 19.1$ & $39.1 \pm 16.2$ \\
\hline & 13 & $0.247 \pm 0.6$ & $97.6 \pm 4.3$ & $87.6 \pm 1.3$ & $92.1 \pm 14.2$ & $81.8 \pm 17.6$ & $70.6 \pm 26.2$ \\
\hline & 20 & $0.261 \pm 0.7$ & $85.4 \pm 7.4$ & $75.2 \pm 9.1$ & $66.7 \pm 11.9$ & $59.0 \pm 11.7$ & $56.0 \pm 10.3$ \\
\hline
\end{tabular}

${ }^{\text {a }}$ Values presented as mean \pm standard deviation $(n=6)$

$P P$ polypropylene, $P V C$ polyvinyl chloride

concentration or storage conditions, there was less than $90 \%$ of the starting concentration remaining after $24 \mathrm{~h}$.

Another divergence in results relates to the storage temperature. Whereas the SPC indicates that the period of stability decreases if the temperature increases, the German study surprisingly observed stability for up to $36 \mathrm{~h}$ at 13-15 ${ }^{\circ} \mathrm{C}$ and lower stability, $19 \mathrm{~h}$, at $2-8{ }^{\circ} \mathrm{C}$. Our results indicate that there is a decrease in stability with an increase in storage temperature; based on a $10 \%$ threshold, stability in PP syringes was $24 \mathrm{~h}$ at $2-8{ }^{\circ} \mathrm{C}, 8 \mathrm{~h}$ at $13-15^{\circ} \mathrm{C}$, and $8 \mathrm{~h}$ at RT. In the study evaluating the polyolefin/polyamide bags, a lower storage temperature was also associated with better stability, at least for the $0.24 \mathrm{mg} / \mathrm{mL}$ solution $(16.7 \mathrm{~h}$ at $4{ }^{\circ} \mathrm{C}$ vs. $8.4 \mathrm{~h}$ at RT) [16]. Interestingly, the stability of the $0.12 \mathrm{mg} / \mathrm{mL}$ solution was largely independent of storage temperature $\left(11.5 \mathrm{~h}\right.$ at $4{ }^{\circ} \mathrm{C}$ vs. $12.0 \mathrm{~h}$ at RT).

The second part of our study was an attempt to explain the reduction in busulfan content on storage. It is well known that busulfan is only slightly soluble in water, which justifies the presence of the solvent DMA in the composition of the pharmaceutical product. In addition, busulfan is not stable in aqueous media as it undergoes hydrolysis, producing methanesulphonic acid and tetrahydrofuran. These two degradation products are not detectable with the chromatographic method used to assay busulfan. This hydrolysis will contribute to the decrease in the busulfan content of preparations over time. However, in this study, we demonstrated that another phenomenon could be the main cause of the decrease in the busulfan content, namely precipitate formation. Precipitation is a phenomenon that is unpredictable and difficult to control, and a number of factors may be involved, particularly container/content interactions as described by Karstens and Krämer [11], temperature, or agitation. So the explanation could be that on one hand there is more agitation of PVC bags and glass bottles than of PP syringes, and on the other hand a higher temperature can promote interactions between the roughness of the container (especially glass) and the content responsible for precipitation. Our study enabled a clearer understanding of this decrease. The initial rapid decline in busulfan content may be due to precipitation, since treatment of early samples with DMA to dissolve any precipitated busulfan resulted in content levels greater than $95 \%$ of the starting levels. Hydrolysis appears to be involved in the subsequent decline in busulfan content.

Reviewing our results, some discrepancies rise, such as that between the 15- and 48-h series measurements. The precipitation phenomenon was attributed as the factor that led to discrepancies, given that the busulfan solution was assessed and did not include the precipitate (which may have contained some busulfan). Furthermore, some samples were precipitated and some were not. When examining the $\mathrm{pH}$ of the solutions, our results demonstrated higher initial $\mathrm{pH}$ values in the PVC bags, and it is thought that this may have arisen via chemical interaction between DMA and the material of the bag. Higher initial osmolarity values were also noted in the PVC bags, which may confirm the potential $\mathrm{pH}$ variations observed in the PVC bags.

\section{Conclusions}

Of the containers studied, PP was the material allowing the longest period of stability for busulfan solutions diluted to a $0.55 \mathrm{mg} / \mathrm{mL}$ concentration. The longest periods of stability were obtained for solutions placed at $2-8{ }^{\circ} \mathrm{C}$, regardless of the container. This study allowed us to understand the decrease of the busulfan content. With hydrolysis degradation, the precipitation phenomen is responsible for busulfan solutions' instability. This phenomen affects other 


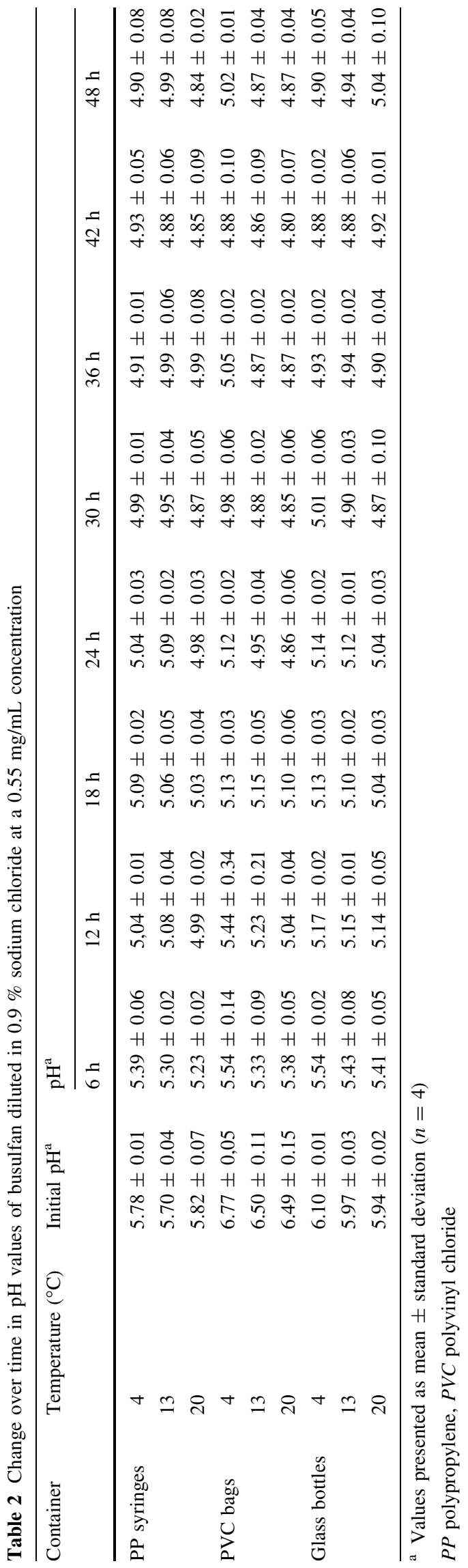

drugs such as fungizone, cytarabine (according to the diluent), or etoposide, according to the concentration. For busulfan, precipitation appears to be temperature related; as the storage temperature increased, the stability of the dilute solutions decreased.

Acknowledgments This study was made possible by the provision of the product by Pierre Fabre Laboratories. We thank Rod McNab, $\mathrm{PhD}$, of inScience Communications, Springer Healthcare, who provided copy editing and journal styling prior to submission. This assistance was funded by Pierre Fabre Laboratories. The authors have no conflicts of interest to declare.

Open Access This article is distributed under the terms of the Creative Commons Attribution Noncommercial License which permits any noncommercial use, distribution, and reproduction in any medium, provided the original author(s) and the source are credited.

\section{References}

1. Galton DA. Myleran in chronic myeloid leukaemia; results of treatment. Lancet. 1953;264:208-13.

2. Scott LJ, Hoy SM, Lyseng-Williamson KA. Intravenous busulfan: a guide to its use as a conditioning treatment before transplantation of haematopoietic progenitor cells. Clin Drug Invest. 2012;32:641-8.

3. Busilvex: summary of product characteristics. London: European Medicines Agency. Available from: http://www.medicines.org. uk/emc/medicine/12967/SPC/.

4. Santos GW. The development of busulfan/cyclophosphamide preparative regimens. Semin Oncol. 1993;20:12-6.

5. Hartmann O, Benhamou E, Beaujean F, et al. High-dose busulfan and cyclophosphamide with autologous bone marrow transplantation support in advanced malignancies in children: a phase II study. J Clin Oncol. 1986;4:1804-10.

6. Valteau-Couanet D, Benhamou E, Vassal G, et al. Consolidation with a busulfan-containing regimen followed by stem cell transplantation in infants with poor prognosis stage 4 neuroblastoma. Bone Marrow Transplant. 2000;25:937-42.

7. Lenarsky C, Parkman R. Bone marrow transplantation for the treatment of immune deficiency states. Bone Marrow Transplant. 1990;6:361-9.

8. Bornhauser M, Storer B, Slattery JT, et al. Conditioning with fludarabine and targeted busulfan for transplantation of allogeneic hematopoietic stem cells. Blood. 2003;11:820-6.

9. Resnick IB, Aker M, Tsirigotis P, et al. Allogeneic stem cell transplantation from matched related and unrelated donors in thalassemia major patients using a reduced toxicity fludarabinebased regimen. Bone Marrow Transplant. 2007;40:957-64.

10. Russell JA, Tran HT, Quinlan D, et al. Once-daily intravenous busulfan given with fludarabine as conditioning for allogeneic stem cell transplantation: study of pharmacokinetics and early clinical outcomes. Biol Blood Marrow Transplant. 2002;8:468-76.

11. Karstens A, Krämer I. Chemical and physical stability of dilued busulfan infusion solutions. Eur J Hosp Pharm Sci. 2007;13:40-7. Available from: http://archive.eahp.eu/Media/Home-page/EJHPBMJ/EJHP-Practice-archive/Issue-2-2007/10th-EAHP-congress-inLisbon/Chemical-and-physical-stability-of-diluted-busulfan-infusio n-solutions.

12. Karstens A, Krämer I. Stability of busulfan injection solution (Busilvex, Busulfex) in B/Braun Injekt syringes. Pharmazie. 2006;61:845-50 (article in German). 
13. Hassan M, Ehrsson H. Degradation of busulfan in aqueous solution. J Pharm Biomed Anal. 1986;4:95-101.

14. ICH Topic Q 2 (R1) Validation of analytical procedures: text and methodology. June 1995 CPMP/ICH/381/95 European Medicinal Agency. Available from: http://www.ema.europa.eu/docs/en_GB/ document_library/Scientific_guideline/2009/09/WC500002662.pdf.

15. Senoo M, Tajika K, Shimizu H et al. Development of new mixing method of busulfex injection for the purpose of improvement of medical safety method: the prefilled syringe method. Yakugaku Zasshi. 2009;129:767-71 (article in Japanese).

16. Nebot Martinez J, Alos Alminana M, Diez Sales O. Stability in serum of intravenous busulfan in a polyolefin pack. Farm Hosp. 2008;32:344-8 (article in Spanish). 